\title{
Optimum Winding Tension and Nip-load into Wound Webs for Protecting Wrinkles and Slippage
}

\author{
Hiromu HASHIMOTO ${ }^{* *}$, Puttha JEENKOUR ${ }^{* * * *}$ \\ and Mongkol MONGKOLOWONGROJN*** \\ ${ }^{* *}$ Department of Mechanical Engineering, Tokai University, \\ 1117 Kitakaname, Hiratsuka City, Kangawa, 259-1292,Japan \\ E-mail: hiromu@keyaki.cc.u-tokai.ac.jp \\ ${ }^{* * \star}$ Department of Mechanical Engineering, ReCClt, RGJ, Faculty of Engineering, \\ King Mongkut's Institute of Technology Ladkarabang, \\ Bangkok, Thailand
}

\begin{abstract}
This paper describes the novel optimization method of wind-up tension to prevent wound roll defects, mainly star defect (wrinkling) and telescoping (slippage), based on the optimum design technique. Modified Hakiel model with air entrainment effects is applied to analyze in-roll stress distributions in the radial and tangential directions. In the present optimization method, the wind-up tension is gradually changed in the radial direction to minimize the tangential stresses under the constraint of nonnegative tangential stresses. At the same time, we consider the friction conditions to prevent the slippage between web layers due to a decrease of radial stresses and friction force. Successive quadratic programming, which is a typical mathematical programming method, is used as the optimization technique. The optimized wind-up tensions are obtained for various winding conditions, and we confirmed theoretically and experimentally that the in-roll stress distributions are very much improved for preventing both wrinkling and slippage simultaneously by the optimization method being proposed.
\end{abstract}

Key words: Web Handling, Wind-up Tension, Slippage, Wrinkling, Optimum Design, Experimental Verification

\section{Introduction}

The web handling processes have been widely used for a lot of products, such as liquid crystal display monitors, mobile phones, solar and fuel cells, and other flexible thin materials related in the printed electronics fields. Most of web handling industries are often encountered with the problems of wrinkling and slippage in the wound roll. Since the winding process is a final stage of the production, these web defects had been a cause of losing a lot of materials and being very high production costs, and wasting a lot of time to restore the wound roll. The generation of wrinkling and slippage in the wound roll is strongly related with the in-roll stress distributions in the wound roll; therefore, it is necessary to understand well the background about stress distributions inside the wound roll. In the past, some researchers investigated theoretically or experimentally into the in-roll stress distributions in the wound roll ${ }^{(1-8)}$.

From these previous studies, it follows that the higher winding tension, higher nip load and higher winding speed become a cause of wrinkling and slippage. The higher winding tension and nip load lead to the wrinkling in the wound roll because of generating the higher radial stresses. On the other hand, the higher winding speed leads to the slippage because of air entrainment between web layers. Since the wrinkling and slippage is trade-off [DOI: 10.1299/jamdsm.4.214]

Copyright $@ 2010$ by JSME 
relation, it is desired to find out the optimum winding tension for protecting both wrinkling and slippage simultaneously. However, as far as the authors know, there is no research work to find out the optimum wind-up tension for preventing both wrinkling and slippage. So, it is required to discover the novel optimization technique which is able to use for solving such kinds of problems in the wound roll. Regarding to optimization technique, Hashimoto et. $\mathrm{al}^{(9)}$ has been developing the geometry optimization method based on the successive quadratic programming (SQP) for the optimum design of the groove geometry of the thrust air bearing. Then, in this paper, this type of optimization technique will be extended to determine the wind-up tension function for preventing both wrinkling and slippage effectively. The obtained results will be compared with the measured data to verify the applicability of the present optimization method.

\section{Nomenclature}

$C_{0} \sim C_{2} \quad$ : coefficients in Eq. (5)

$E_{c} \quad:$ Young's modulus of core $[\mathrm{Pa}]$

$E_{\text {nip }} \quad$ : Young's modulus of nip roll [Pa]

$E_{r} \quad:$ radial Young's modulus of wound roll [Pa]

$E_{r a} \quad:$ Young's modulus of air layer [Pa]

$E_{\text {req }} \quad:$ equivalent radial Young's modulus of wound roll [Pa]

$E_{t} \quad:$ tangential Young's modulus of wound roll $[\mathrm{Pa}]$

$E_{\text {teq }} \quad$ : equivalent tangential Young's modulus of wound roll [Pa]

$f(\boldsymbol{X}) \quad$ : objective function

$F_{\text {cr }} \quad:$ critical friction force to start slippage [N]

$F_{i} \quad:$ friction force between web layers in wound roll [N]

$\bar{F}_{i} \quad:$ averaged values of friction force between web layers $[\mathrm{N}]$

$g_{\mathrm{i}}(\boldsymbol{X})(i=1 \sim 2 n+4) \quad$ : constraint functions

$h \quad:$ thickness of air layer under winding [m]

$h_{0} \quad:$ thickness of air layer at the outermost radius [m]

$N \quad: \operatorname{nip}$ load [N]

$p_{a} \quad:$ atmospheric pressure $[\mathrm{Pa}]$

$r \quad:$ arbitrary radius of wound web layer $[\mathrm{m}]$

$r_{c} \quad:$ radius of winding core [m]

$r_{\max } \quad:$ maximum radius of wound roll $[\mathrm{m}]$

$s \quad$ : outermost radius of wound roll $[\mathrm{m}]$

$t_{f} \quad:$ web thickness at arbitrary radius of wound roll $[\mu \mathrm{m}]$

$t_{f 0} \quad:$ web thickness at the initial stage of winding $[\mu \mathrm{m}]$

$T_{w}(r) \quad$ : wind-up tension function $[\mathrm{N} / \mathrm{m}]$

$T_{w 0}(r) \quad:$ initial wind-up tension function $[\mathrm{N} / \mathrm{m}]$

$\Delta T_{i}(i=1 \sim n) \quad:$ tension variation from initial tension at the $i$ th node $[\mathrm{N} / \mathrm{m}]$

$U_{w} \quad:$ winding-up velocity of web $[\mathrm{m} / \mathrm{s}]$

$W \quad$ : web width [m]

$\boldsymbol{X} \quad$ : design variable vector

$\mu_{\text {eff }} \quad$ : effective friction coefficient between web layers

$\mu_{s} \quad:$ static friction coefficient between web layers

$v_{r t} \quad$ : Poisson's ratio of wound roll

$\sigma_{f f} \quad:$ composite surface roughness between web layers $[\mu \mathrm{m}]$

$\sigma_{r} \quad:$ radial stress in wound roll $[\mathrm{Pa}]$

$\delta \sigma_{r} \quad:$ increment of radial stress $[\mathrm{Pa}]$

$\sigma_{t} \quad:$ tangential stress in wound roll $[\mathrm{Pa}]$

$\phi \quad$ : taper ratio of tapered wind-up tension 


\section{Analytical Model of In-Roll Stresses in Wound Roll}

The radial and tangential in-roll stresses $\sigma_{r}$ and $\sigma_{t}$ as shown in Fig.1 are important factors to understand the physical situations inside the wound roll, because there is strong relation between the web defects and the in-roll stress distributions. For example, when the web is wound under high winding tension or high nip load, some wrinkles as shown in Fig. 2(a) (generally called star defect) will appear. On the other hand, when the web is wound under the high winding speed or low winding tension, the slippage as shown in Fig. 2 (b) (generally called telescoping) is easily generated near the outermost radius of wound roll. Among these roll defects, the star defect is thought to be a buckling phenomenon that occurs due to the fact that the tangential stress $\sigma_{t}$ becomes negative and a compressive force acts along the tangential direction of wound web layers. Consequently, to prevent this kind of phenomenon, it is required that the tangential stress does not become negative. On the other hand, when the tangential stress is positive, there is the possibility that the web will be stretched and generated the creep phenomenon. Accordingly, to prevent both star defect and creep simultaneously it is necessary to set up the winding-up conditions before winding so that the tangential stresses of the wound roll are nonnegative, uniform and approaching zero in the radial direction as much as possible.

Some causes of telescoping, however, are a slippage that occurs between web layers because the external force in the axial direction is unable to be supported due to the lowering of the radial compressive stress between web layers or due to the entrainment of air in the wound roll. Consequently, to prevent telescoping, it is necessary to set up the winding-up conditions so that the friction forces and radial compressive stresses maintain a suitable level, and the thickness of the air layer becomes as thin as possible.

Figure 3 shows a conceptual diagram of the most basic center drive winding with a nip roll. It has been confirmed that the Hakiel model ${ }^{(5)}$ is effective to analyze the in-roll stresses but the model does not include the effects of air entrainment and nip load and can not be applied directly to this kind of winding system. Therefore, in this research work, the modified Hakiel model considering the effects of air entrainment and nip load is used. The formulation of the modified Hakiel model is described briefly below.

The radial stress $\sigma_{\mathrm{ri}}$ at the $i$ th layer of a wound roll is found by adding all radial stress increments in each layer from the $i+1$ layer up to the $n$th layer (final layer of winding) as follows;

$$
\sigma_{r i}=\sum_{j=i+1}^{n} \delta \sigma_{r i j}
$$

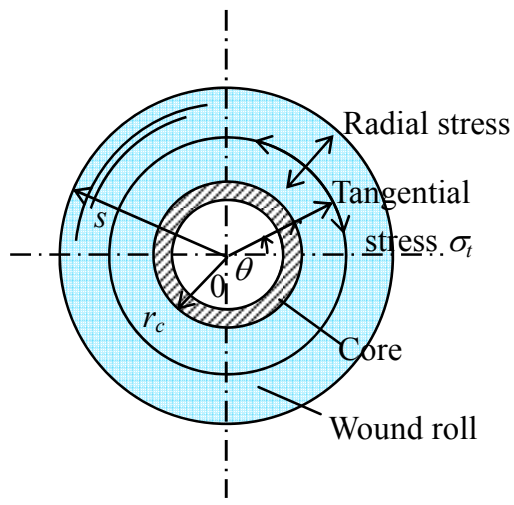

Fig. 1 In-roll stresses

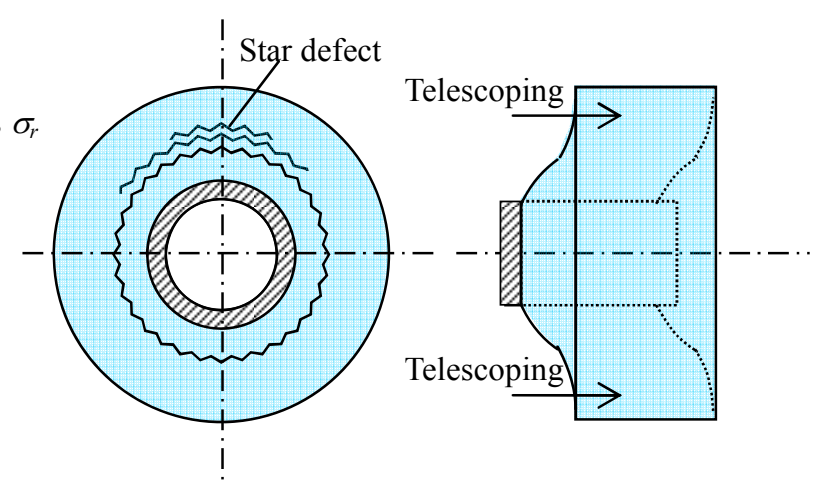

(a) Wrinkling

(b) Slippage

Fig. 2 Typical web defect in wound roll 


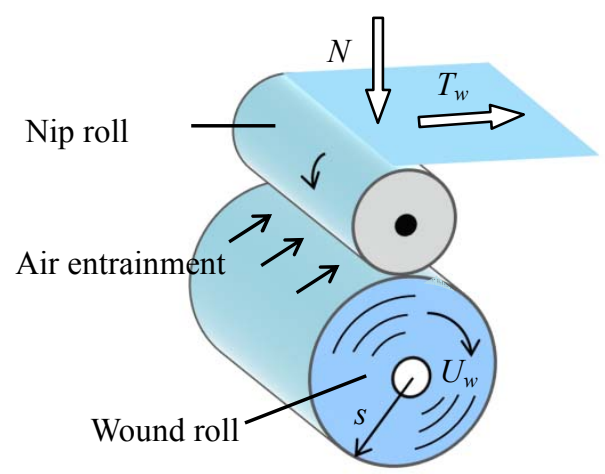

Fig.3 Center drive winding with a nip roll

where, $\delta \sigma_{\mathrm{rij}}$ represents the radial stress increment in the $j$ th layer when the web is wound up to the $i$ th layer, and the equation that controls $\delta \sigma_{r i j}$ (hereafter the subscripts $i$ and $j$ are omitted ) is given as follows.

$$
r^{2} \frac{d^{2} \delta \sigma_{r}}{d r^{2}}+\left(3-v_{r t}\right) r \frac{d \delta \sigma_{r}}{d r}+\left(1+v_{r t}-\frac{E_{t e q}}{E_{r e q}}\right) \delta \sigma_{r}=0
$$

Considering the nip-induced tension, the boundary conditions at the outermost and innermost radii of the roll are set, respectively, as follows.

$$
\left.\delta \sigma_{r}\right|_{r=s}=-\frac{\left.T_{w}\right|_{r=s}+\mu_{e f f} N / W}{s},\left.\frac{d \delta \sigma_{r}}{d r}\right|_{r=r_{c}}=\left(\frac{E_{t e q}}{E_{c}}-1+v_{r t}\right) \frac{\left.\delta \sigma_{r}\right|_{r=r_{c}}}{r_{c}}
$$

Using the relationship between the stress and strain of the equivalent layer of the collective thickness $\left(t_{f 0}+h_{0}\right)$ and Boyle's law, the equivalent radial and tangential Young's moduli $E_{\text {req }}$ and $E_{\text {teq }}$ considering the air entrainment, in Eqs. (2) and (3), can be found as follows;

$$
E_{r e q}=\frac{t_{f_{0}}+h_{0}}{t_{f_{0}} / E_{r}+h_{0} / E_{r a}}, \quad E_{\text {teq }}=\frac{t_{f}}{t_{f}+h} E_{t}
$$

where Young's modulus of the air layer $E_{r a}$ can be given as follows.

$$
E_{r a}=\frac{\left(\left|\sigma_{r}\right|+p_{a}\right)^{2}}{\left(\left.T_{w}\right|_{r=s}+\mu_{e f f} N / W\right) / s+p_{a}}
$$

Moreover, in the process of winding, the web thickness $t_{f}$ and air film thickness $h$ at arbitrary radius can be given, respectively, as follows.

$$
t_{f}=\left(1-\frac{\delta \sigma_{r}}{E_{r}}\right) t_{f_{0}} \quad h=\left(\frac{\left(\left.T_{w}\right|_{r=s}+\mu_{e f f} N / W\right) / s+p_{a}}{\left|\sigma_{r}\right|+p_{a}}\right) h_{0}
$$


In the above Eqs.(4) and (6), $h_{0}$ and $t_{f 0}$ mean the entrained air film thickness and web thickness at the initial stage of winding.

When an air is entrained at the time of web winding, the pressure between the web layers of wound roll lowers and a slippage occurs easily. Accordingly, for the purpose of causing amount of entrained air to be decreased as much as possible and preventing slippage, the center drive winding is often carried out using a nip roll shown in Fig. 3 . The initial entrained air film thickness $h_{0}$ of this case can be evaluated by the elastohydrodynamic lubrication theory of the line contact between the wound roll and nip roll. In this work, the formula established by Hamrock and Dowson ${ }^{(10)}$ is used to evaluate the entrained air film thickness $h_{0}$.

The relationship between the radial stress $\sigma_{\mathrm{r}}$ and Young's modulus $E_{r}$ becomes nonlinear, and it is represented by the following empirical equation;

$$
E_{r}=C_{0}+C_{1}\left|\sigma_{r}\right|^{C_{2}}
$$

provided that the coefficients $C_{0}-C_{2}$ in Eq.(7) are constants that can be found experimentally.

Based on the equilibrium condition of in-roll stresses, the tangential stress $\sigma_{\mathrm{t}}$ can be found from the following equation using the radial stress $\sigma_{\mathrm{r}}$ that can be obtained from the above mentioned Eqs. (1)-(7).

$$
\sigma_{t}=r \frac{d \sigma_{r}}{d r}+\sigma_{r}
$$

\section{Optimization Method of Wind-Up Tension}

The wind-up tension is a very important parameter that exerts a large influence on the in-roll stresses of the wound roll, which is the main cause of roll defects. Accordingly, in this work, we challenge to discover the new optimization method of the wind-up tension and nip load, concerning an effective method of preventing both star defect (wrinkle) and telescoping (slippage) effectively that have a comparatively high frequency of occurrence in the web handling industries. The method is described below.

For a long time, the method of causing the tapered wind-up tension to decrease the tension in proportion to the radial position of wound roll has been used to prevent the occurrence of a star defect. However, this method was established depending on the experiences at the production lines of factories, and there is no theoretical guarantee that it gives the optimal wind-up condition to prevent the star defect.

Accordingly, in this work, the tension function $T_{w}(r)$ will be determined by applying the geometry optimization method proposed by Hashimoto et al. ${ }^{(9)}$ on the condition that the minimum value of the tangential stress in the wound roll $\sigma_{t}$ becomes nonnegative and the averaged values of the tangential stresses approaches to zero level as much as possible.

In dealing with the expression of a common tension function $T_{w}(r)$, taking into consideration the flexibility and ease of handling of a function, the following cubic spline function is employed.

$$
\begin{aligned}
T_{w}(r)= & \frac{M_{i}}{6 \Delta r}\left(r_{i+1}-r\right)^{3}+\frac{M_{i}}{6 \Delta r}\left(r-r_{i}\right)^{3}+\left(T_{i}-\frac{M_{i} \Delta r^{2}}{6}\right)\left(\frac{r_{i+1}-r}{\Delta r}\right) \\
& -\left(T_{i+1}-\frac{M_{i+1} \Delta r^{2}}{6}\right)\left(\frac{r-r_{i}}{\Delta r}\right)
\end{aligned}
$$




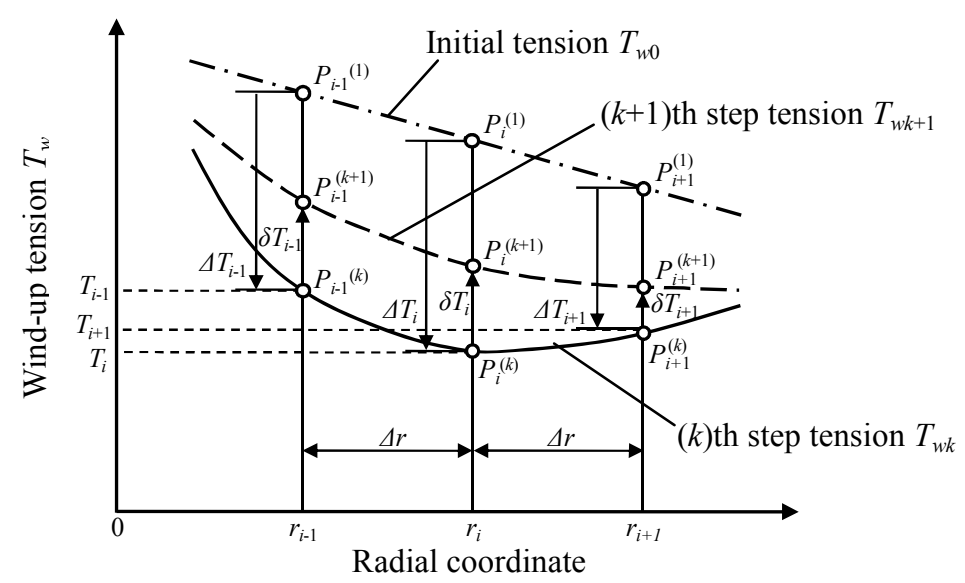

Fig. 4 Evolution of wind-up tension under optimization process

In Eq. (9) the symbol $\Delta r$ is an equally divided section of the radial coordinate $r$, and $M_{i}$ is the shape parameter determined from the condition in which the first derivative of Eq.(9) becomes continuous at each nodal point.

When the tension function $T_{w}(r)$ is caused to evolve sequentially, the $r$ coordinate of each nodal point $P^{(k)}\left(r_{i}, T_{i}\right)$ is fixed with respect to the tension function of the previous stage ( $k$ step) in the evolutive process $((k+1)$ step), shown by the broken lines in Fig. 4, and the coordinate of $T_{w}$ is caused to change only $\delta T_{i}$ in the positive direction or the negative direction and to obtain a new nodal point $P_{i}^{(k+1)}\left(r_{\mathrm{i}}, T_{i}+\delta T_{i}\right)$. The function form is updated via Eq. (9) using the new coordinate value that could be obtained in this way and is caused to sequentially evolve until the value of the objective function $f(X)$ mentioned later becomes optimum.

Based on the above considerations, the design variable vector is set as follows;

$$
\boldsymbol{X}=\left(\Delta T_{1}, \Delta T_{2}, \Delta T_{3}, \cdots, \Delta T_{n}, N\right)
$$

where the feasible region of the optimization is divided into $n$ regions in the $r$ direction from the outer radius of core up to the outermost radius of wound roll, and $\Delta T_{i}$ means the difference between the initial tension $T_{w 0}$ and the partially evolved ( $k$ step) tension at an arbitrary radius position $r_{i}$, and $N$ means the nip load to be optimized simultaneously.

The objective function $f(\boldsymbol{X})$ is defined by the following equation;

$$
f(\boldsymbol{X})=\sum_{i=1}^{n}\left\{\left(\frac{F_{i}}{F_{c r}}-1\right)^{2}+\left(\frac{\sigma_{t i}}{\sigma_{t, r e f}}\right)^{2}\right\}
$$

where $F_{i}$ means the friction force between web layers, $F_{c r}$ means the critical friction force to start the slippage, which was determined experimentally as $F_{c r}=5 \mathrm{kN}$ (equivalent to the impact acceleration of $50 \mathrm{~g}$ ), and $\sigma_{t, \text { ref }}$ means the reference value of tangential stress respectively. $F_{i}$ and $\sigma_{t, \text { ref }}$ are determined, respectively, by Eq. (12).

$$
F_{i}=2 \pi r_{i} \mu_{e f f}\left|\sigma_{r i}\right| W, \quad \sigma_{t, r e f}=T_{w 0} / t_{w 0}
$$

On the other hand, the constraint conditions that can be imposed on the upper and lower 
limits of the design variables $\Delta T_{i}$, nip load $N$, the minimum value of tangential stress $\sigma_{t \min }$ and the averaged value of friction forces between web layers $\bar{F}_{i}$ are represented by the following inequality expressions.

$$
g_{i}(X) \leq 0 \quad(i=1 \sim 2 n+4)
$$

In Eq. (13), the constraint functions $g_{i}(\boldsymbol{X})(i=1 \sim 2 n+4)$ are defined as follows.

$$
\left.\begin{array}{l}
g_{1}=\Delta T_{1 \min }-\Delta T_{1}, g_{2}=\Delta T_{1}-\Delta T_{1 \max } \\
g_{3}=\Delta T_{2 \min }-\Delta T_{2}, g_{4}=\Delta T_{2}-\Delta T_{2 \max } \\
\quad \vdots \\
g_{2 n-1}=\Delta T_{n \min }-\Delta T_{n}, g_{2 n}=\Delta T_{n}-\Delta T_{n \max } \\
g_{2 n+1}=N_{\min }-N \quad, g_{2 n+2}=N-N_{\max } \\
g_{2 n+3}=-\sigma_{t \min }, \\
g_{2 n+4}=F_{c r}-\bar{F}_{i}\left(\text { for } r \leq 0.95 r_{\max }\right)
\end{array}\right\}
$$

Summarizing these equations, the optimization problem of wind-up tension is expressed as follows.

$$
\begin{aligned}
& \text { Find } X \text { to minimize } f(\boldsymbol{X}) \\
& \qquad \begin{array}{l}
\text { subject to } g_{i}(\boldsymbol{X}) \leq 0 \quad(i=1 \sim 2 n+4)
\end{array}
\end{aligned}
$$

\section{Experiments}

In this work, the experiments consist of measuring the in-roll radial stresses of wound roll and the impact load test to observe whether the slippage will occur or not after winding. Figure 5 shows the diagram of a winding machine, specially designed and manufactured for the present work, which has the control system to control the wind-up tension covering the constant, tapered and optimized tensions, nip load and web winding velocity. The thin plastic film (PET) is transferred from the wound out roll to the wound in roll through the pinch roller and nip roll, and reeled finally. During the operation of winding, five to seven force-sensitive resistors as shown in Fig.6 are inserted between the wound web layers for measuring the radial stress distributions. When the external force is applied to the sensor, the resistance would be changed, and then, by measuring the resistance the radial stresses can be known with the calibration results of the relation between the pressure and resistance. As can be seem in Fig. 6, the sensor is covered with film. In the previous experimental

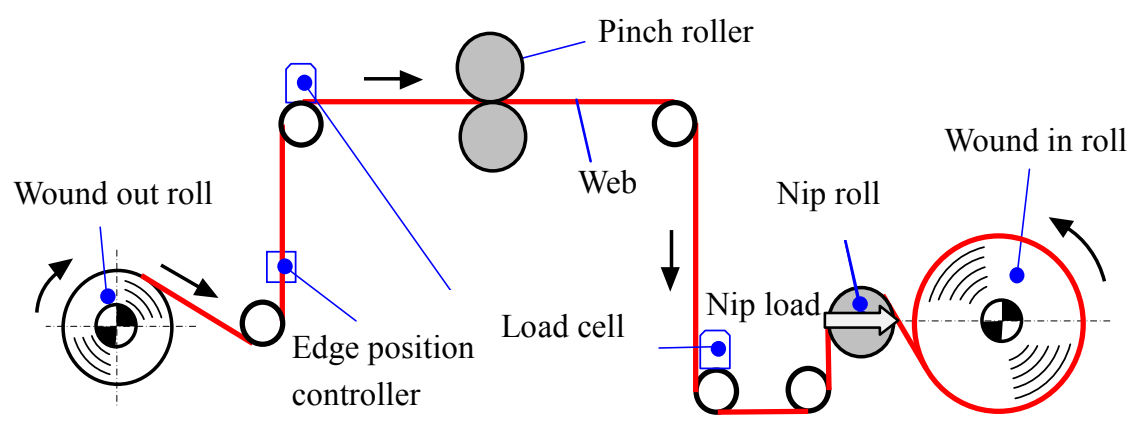

Fig. 5 Experimental apparatus 


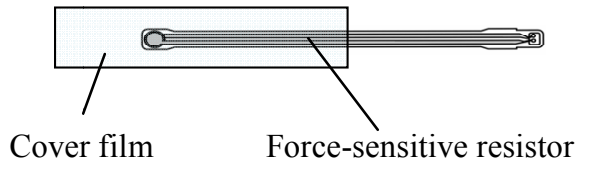

Fig. 6 Force-sensitive resistor modified with cover film

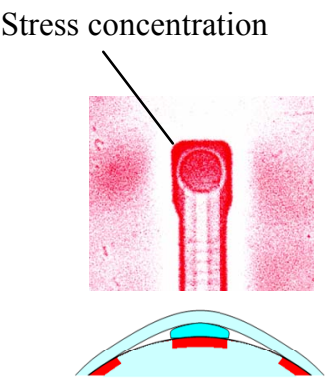

(a) Without cover film
No stress concentration
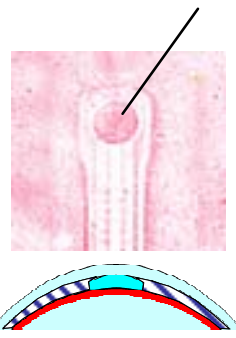

(b) With cover film

Fig. 7 Stress concentration at sensing part

research works by several investigators, the force-sensitive resistor without cover film has been used directly for measuring the in-roll radial stresses of wound roll. In this case, however, the stress concentration occurs at the sensing part and it necessarily leads to higher radial stress in the sensing part as shown in Fig. 7(a). To avoid this serious problem, we propose to use the modified sensor with cover film as shown in Fig. 6. Using this type of modified sensor, the stress concentration can be avoided as shown in Fig. 7(b).

The impact load test procedure to confirm the occurrence of slippage in the wound roll is shown in Fig. 8. Figure 8 (a) shows the testing of slippage by falling the wound roll down to the base, in which the distance of falling was set at $10 \mathrm{~cm}$ (equivalent to the impact of $50 \mathrm{~g}$ ). After the wound roll was crashed against the base, the amount of slippage was observed and measured by scanning the optical sensor along the radial direction as shown in Fig.8(b).

\section{Results and Discussions}

In this work, the PET film was used as a test web. The physical properties of PET film, core roll, and nip roll are listed in Table 1. The measured and predicted results concerning with the in-roll stress distributions and the friction forces under the constant, tapered, and optimized wind-up tensions will be presented in the following. The experimental results of the tangential stresses and friction forces in the wound roll were obtained indirectly via Eqs. (8) and (12) by using the appropriate curve fitting of the experimental data on the radial stress distributions.

Usually, in the web handling industries, the tapered tension has been widely used as wind-up tension to prevent the generation of wrinkling. Therefore, at first, we try to check

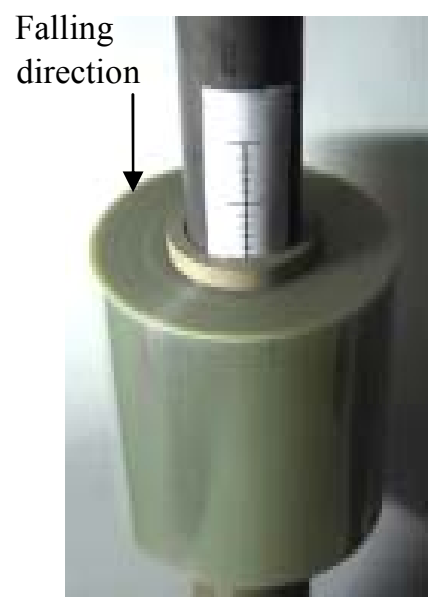

(a) Falling test

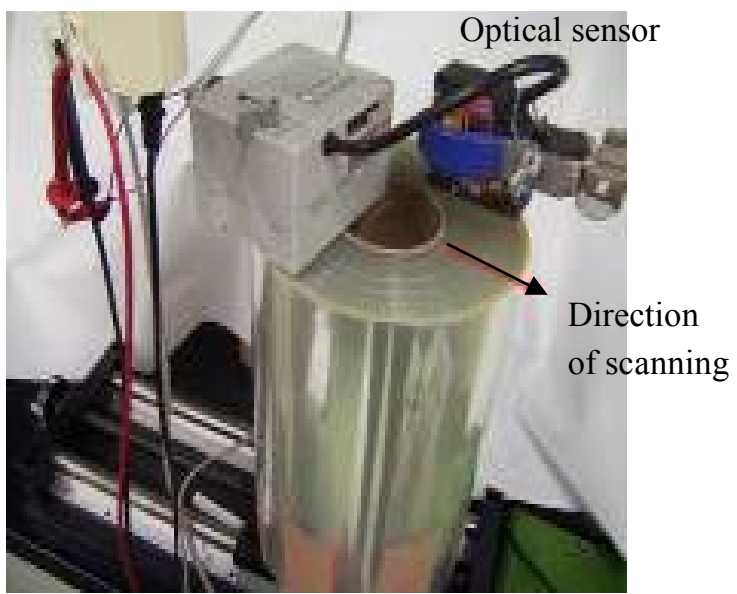

(b) Surface scanning test

Fig. 8 Impact load test for observing slippage 
Table 1 Physical properties of PET film, core roll and nip-roll

\begin{tabular}{|c|c|c|}
\hline Composite roughness between web layers & $\sigma_{f f}, \mu \mathrm{m}$ & 0.066 \\
\hline Web thickness & $t_{f}, \mu \mathrm{m}$ & 50 \\
\hline Web width & $W, \mathrm{~m}$ & 0.28 \\
\hline Tangential Young's modulus of wound roll & $E_{t}, \mathrm{~Pa}$ & $4.8 \times 10^{9}$ \\
\hline Radial Young's modulus of wound roll & $E_{r}, \mathrm{~Pa}$ & $\begin{array}{l}E_{r}=C_{0}+C_{1}\left|\sigma_{r}\right|^{C_{2}} \\
C_{0}=0, \quad C_{1}=4.09 \times 10^{4} \\
C_{2}=0.65\end{array}$ \\
\hline Poisson's ratio of wound roll & $v_{r \theta}$ & 0.03 \\
\hline Young's modulus of core & $E_{c}, \mathrm{~Pa}$ & $1.3 \times 10^{9}$ \\
\hline Winding core radius & $r_{c}, \mathrm{~m}$ & 0.05 \\
\hline Static friction coefficient between webs & $\mu_{\mathrm{s}}$ & 0.3 \\
\hline Young's modulus of nip-roll & $E_{\text {nip }}, \mathrm{Pa}$ & $2.06 \times 10^{11}$ \\
\hline
\end{tabular}

the effectiveness of tapered tension for preventing the wound roll defects. Figure 9 shows the in-roll stress and friction force distributions in the wound roll under the conventional tapered wind-up tensions with taper ratio of $\phi=0,0.4$ and 0.8 shown in Fig.9 (a). As can be seen in Figs. 9 (b) and 9 (c), in the cases of taper ratio of $\phi=0.4$ and 0.8 , the radial stresses become lower than the case of constant winding tension with $\phi=0$ and then the tangential stresses become positive that could prevent the wrinkling in the wound roll. However, the possibility of generating creep becomes higher as the taper ratio increases because the wound web will be stretched in the tangential direction due to the higher tangential stresses. On the other hand, Fig. 9 (d) shows a decrease of the friction force between the web layers when the taper ratio is set at $\phi=0.4$ and 0.8 . Especially, in the case of the taper ratio of $\phi$ $=0.8$, the friction force at the normalized radial range from $r / r_{c}=1.8$ to 2.0 becomes smaller than the critical slippage line, and in such region the slippage is easy to occur.

From the above results obtained for both cases of constant and tapered tensions, it follows that the tapered tension has an advantage of preventing the wrinkling but has disadvantage of occurrence of creep and slippage. Therefore, the development of the optimization method of wind-up tension instead of the conventional tapered tension is strongly required to prevent both wrinkling and slippage effectively.

Figure 10 shows one of examples of the evolution process of the wind-up tension from the initial tapered tension with $\phi=0.8$ to the optimized tension for the winding speed of $U_{w}$ $=0.5 \mathrm{~m} / \mathrm{s}$. In this case, the nip load was fixed at $N=50 \mathrm{~N}$ and the upper and lower limits of $\Delta T_{i}$ were set at $\Delta T_{i \min }=0$ and $\Delta T_{i \max }=T_{w 0}$. The optimized wind-up tension as shown in Fig. 10(a) was successfully obtained for eight to ten repetitions of numerical calculation, and it was confirmed that the quite same optimized tension was obtained for various initial wind-up tensions with different taper ratios. As can be seen in Figs.10 (b) and 10(c), the radial stress under the optimized wind-up tension becomes lower and nearly constant for a wide range in the radial direction with a suitable level, and then the tangential stress becomes zero level but not below zero. This type of tangential stress distribution has an advantage to prevent both wrinkling and creep simultaneously in the wound roll. In addition, Fig.10 (d) shows the possibility of preventing the slippage in the wound roll due to the suitable level of friction force more than the critical slippage line.

Figure 11 shows the tangential stress and friction force distributions for optimizing both wind-up tension and nip load simultaneously for relatively high winding velocity of $U_{w}=1.0 \mathrm{~m} / \mathrm{s}$, in which the results for optimizing the wind-up tension with a fixed nip load are also indicated. In this case, the upper and lower limits of a nip load were set at $N_{\min }=0$ and $N_{\max }=100 \mathrm{~N}$, and the optimized nip load was determined as $N_{\text {opt }}=81.4 \mathrm{~N}$. As can be 


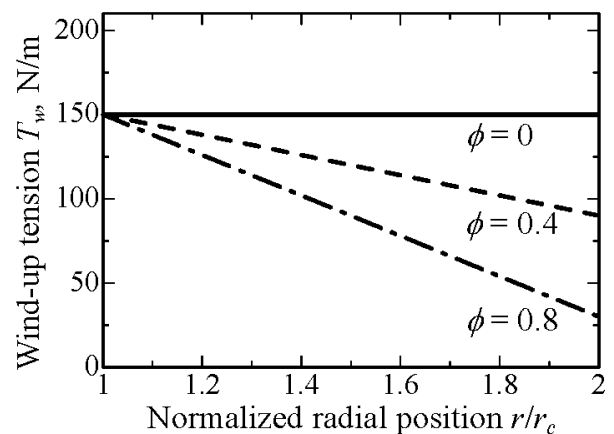

(a) Wind up tension

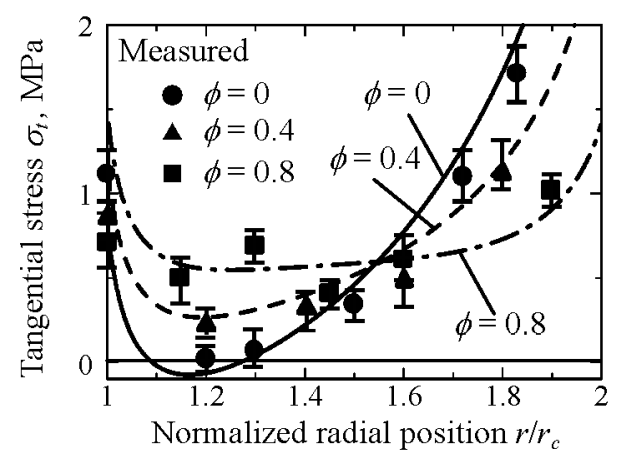

(c) Tangential stress

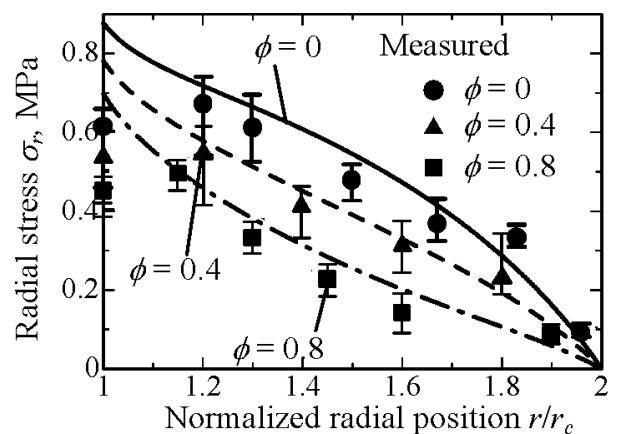

(b) Radial stress

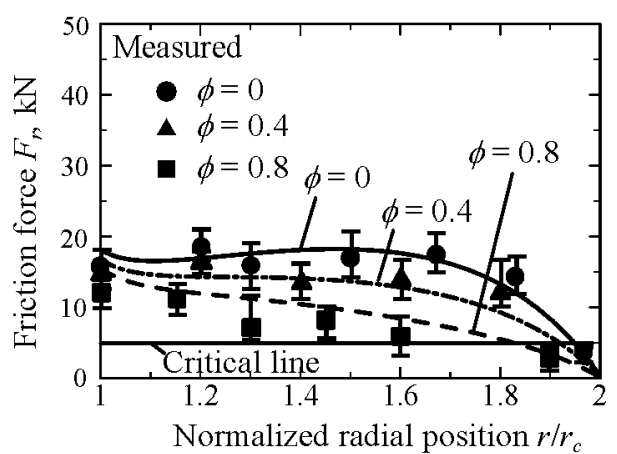

(d) Friction force

Fig.9 In-roll stress and friction force distributions under the conventional tapered tension force distributions $\left(U_{w}=0.5 \mathrm{~m} / \mathrm{s}, N=50 \mathrm{~N}\right)$

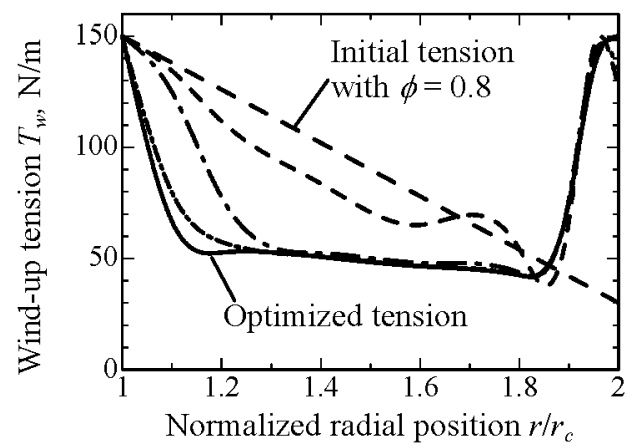

(a) Wind up tension

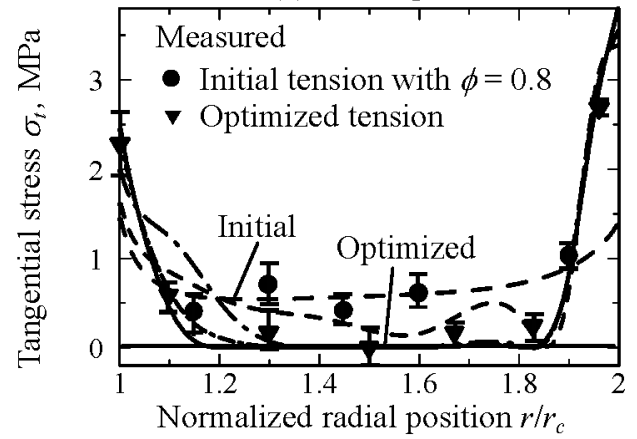

(c) Tangential stress

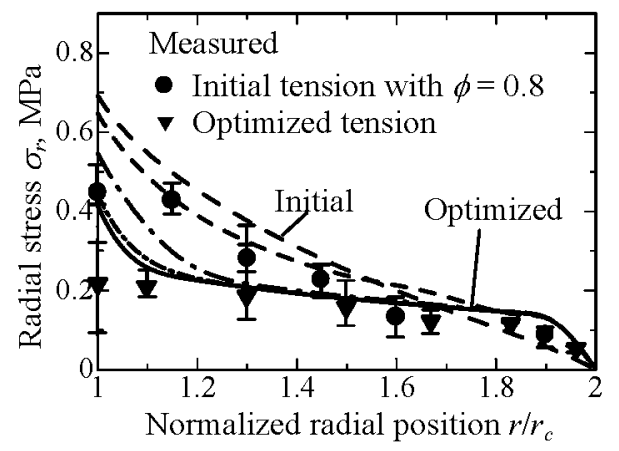

(b) Radial stress

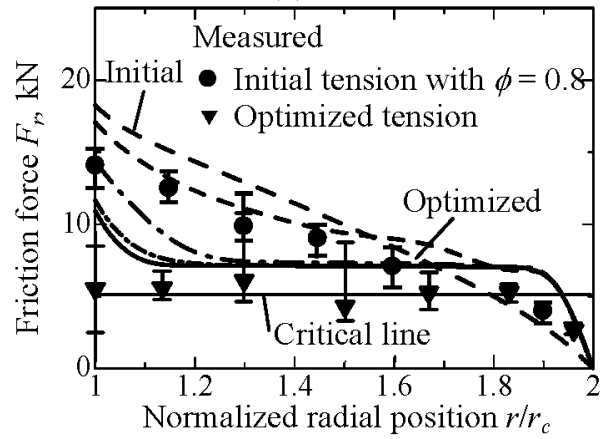

(d) Friction force

Fig.10 In-roll stress and friction force distributions in the process of optimization

$$
\left(U_{w}=0.5 \mathrm{~m} / \mathrm{s}, N=50 \mathrm{~N}\right)
$$

seen in Fig.11 (a), the wind-up tension under the optimization of both wind-up tension and nip load becomes lower than that under the optimization of wind-up tension only. Fig.11 (d) shows the friction force distributions for both cases. The radial stress and friction force for 


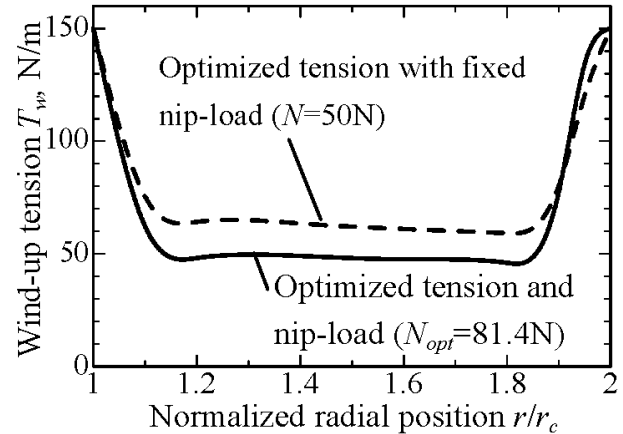

(a) Wind-up tension

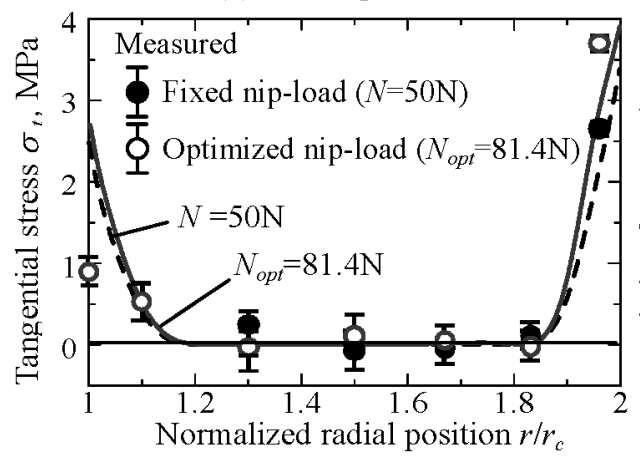

(c) Tangential stress

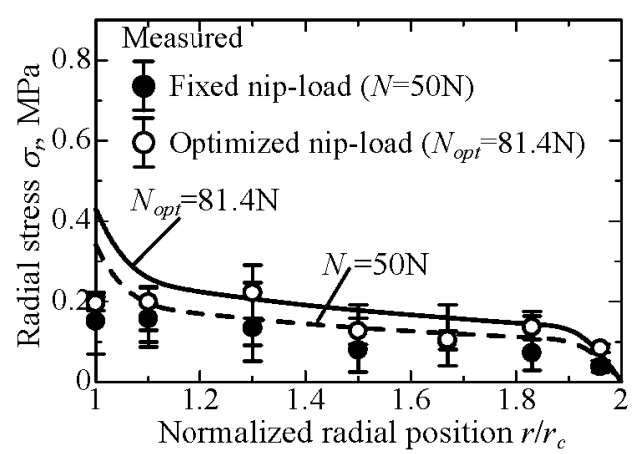

(b) Radial stress

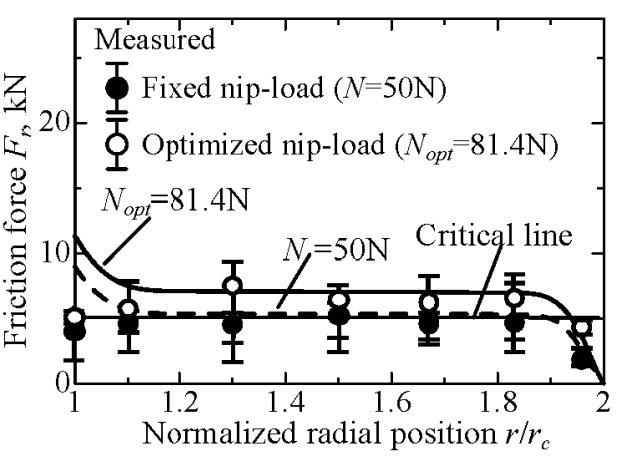

(d) Friction force

Fig.11 Tangential stress and friction force distributions under optimized tension and nip load $\left(U_{w}=1.0 \mathrm{~m} / \mathrm{s}\right)$

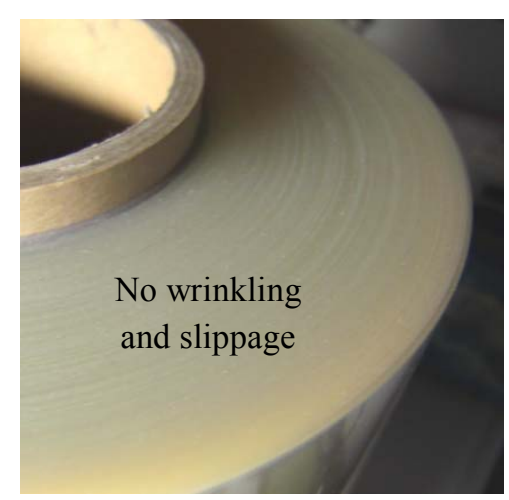

(a) Under optimized tension

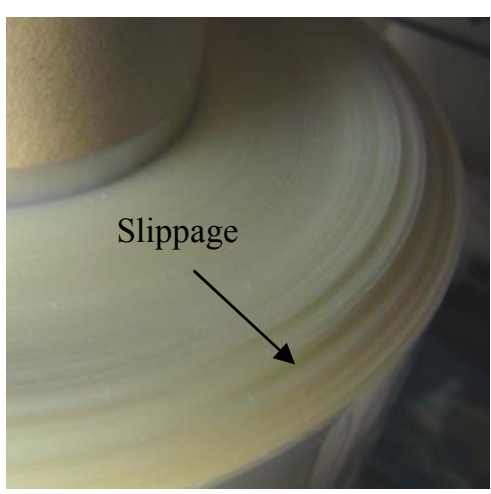

(b) Under tapered tension $(\phi=0.8)$

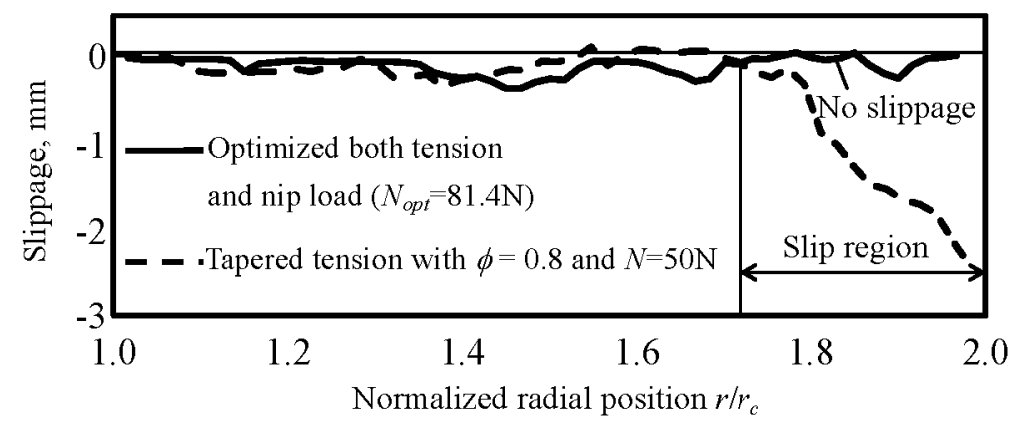

(c) Amount of slippage

Fig.12 Slippage observation after impact load test $\left(U_{w}=1.0 \mathrm{~m} / \mathrm{s}\right)$

optimizing both wind-up tension and nip load $\left(N_{\text {opt }}=81.4 \mathrm{~N}\right)$ become larger than those for optimizing the wind-up tension only with the fixed nip load of $N=50 \mathrm{~N}$, although the optimized wind-up tension in the former case becomes smaller than that in the later case as shown in Fig.11 (a). From this fact, it is considered that the effect of nip load on the friction 
force is little more sensitive as compared with the effect of wind-up tension.

Figure 12 shows the results of impact load test to observe the occurrence of slippage after winding. In the case of the tapered tension with the fixed nip load, $\phi=0.8$ and $N=50 \mathrm{~N}$, the slippage was observed clearly in the outer radius region of wound roll. However, in the case of optimizing both wind-up tension and nip load simultaneously, which is presented in Fig.11(a), no slippage and wrinkling can be seen, and the effectiveness of optimization method newly developed in this work was verified experimentally.

\section{Conclusions}

(1) The novel method of representing an arbitrary wind-up tension by a cubic spline function concerning with the radial coordinate and of evolving gradually the wind-up tension function based on the optimization technique to realize the in-roll stress distributions in which the wrinkling, creep and slippage do not occur was developed.

(2) It was verified theoretically and experimentally that the in-roll stress and friction force distributions in the wound roll are very much improved and it is possible to prevent the wrinkling, creep and slippage effectively based on the present optimization method.

\section{Acknowledgement}

The authors wish to acknowledge the financial support of the Ministry of Education, Culture, Sports, Science and Technology of Japan under the Grant in Aid for Scientific Research A(No.19206021). This paper was also partially supported by RGJ in Thailand, which had been supported about the finance for student during conducting research in Tokai University, Japan.

\section{References}

(1) Gutterman, R.P., "Theoretical and Practical Studies of Magnetic Tape Winding Tensions and Environmental Roll Stability," US Contract No. DA-18-119-sc-42, 1959.

(2) Catlow, M. G., and Walls, G. W., "A Stability of Stress Distribution in Pirns," Journal of Textile Institute, Part3., 1962, pp.410-429.

(3) Yogoda, H.P., "Integral Formulas for Wound Rolls," Mechanic Research Communications, Vol.7, No.2, 1980, pp.103-112.

(4) Pfeiffer, J.D., "Internal Pressures in a Wound Roll," Tappi Journal, Vol.49, No.8, 1966, pp.342-343.

(5) Hakiel, Z., "Nonlinear Model for Wound Roll Stresses," Tappi Journal, Vol.70, No.5, 1987, pp.113-117.

(6) Good, J.K., and Covell, S.M., "Air Entrainment and Residual Stresses in Rolls Wound with a Rider Roll," Proceedings of the $3^{\text {rd }}$ International Conference on Web Handling, 1995, pp.95-112.

(7) Sasaki, M., Tanimoto, K., Kohno, K., Takahashi, S., Kometani, H., and Hashimoto, H., "In-Roll Stress Analysis Considering Air-Entrainment at the Roll-Inlet with the Effect of Grooves on Nip Roll Surface,” JSME J. Advanced Mechanical Design, Vol.2, 2008, pp.133-145.

(8) Lin, P. M., and Wickert, J.A., "Corrugation and Buckling Defects in Wound Rolls," Journal of Manufacturing Science and Engineering ASME, Vol.128, 2006, pp.56-64.

(9) Hashimoto, H., and Ochiai, M., "Optimization of Groove Geometry for Thrust Air Bearing to Maximize Bearing Stiffness," Journal of Tribology ASME, Vol.130, 2008, pp.1-11.

(10) Hamrock, B. J., and Dowson, D., "Elastohydrodynamc Lubrication of Elliptical Contacts to Materials of Low Modulus I-Fully Flooded Conjunction," ASME J. Lubrication Technology, Vol.100, 1978, pp.236-245. 